\title{
A criação dramatúrgica e a encenação a partir do teatro estático de Fernando Pessoa
}

\author{
RICARDO BOLÉO
}

Fernando Pessoa's plays or just a few fragments of these have been staged in Portugal over the past sixty years, alongside the author's poetry. In this essay we take as an example the experience, in the first person, of dramaturgical creation and staging based on texts from Fernando Pessoa's static drama, in order to demonstrate that these plays give contemporary creation a theatrical aesthetic that is not defined by the literary form or category but by the characteristics that come from a meticulous choice of words by the author.

STATIC DRAMA / INTERIORITY / DRAMATURGY / SILENCE / THEATRICAL AESTHETICS

O TEATRO ESTÁTICO DE FERNANDO PESSOA NOS PALCOS PORTUGUESES

Maurice Maeterlinck propõe, em 1896, a noção de «teatro estático» no ensaio «Le tragique quotidien» sugerindo que a introdução de conceções filosóficas no teatro revelassem um género que se opusesse ao teatro naturalista, muito em voga à época.

$O$ Marinheiro, peça de teatro que Fernando Pessoa denominou «drama estático em um quadro», foi publicada no primeiro número de Orpheu. Pessoa enalteceu as qualidades deste texto «em detrimento da subtileza simbolista comummente atribuída à produção dramatúrgica de Maeterlinck» (Fischer, 2012). A peça data de 11/12 de outubro de 1913, portanto alguns meses antes do dia 8 de março de 1914, a que Fernando Pessoa chamou o «dia triunfal», em que Alberto Caeiro terá surgido pela primeira vez. Embora a experiência dramatúrgica preceda a «experiência dramatúrgica da heteronímia» (Freitas/Ferrari, 2017a: 9), O Marinheiro parece preconizá-la: em cena três veladoras, «que, como os principais heterónimos de Pessoa, são três» (Boléo, 2014: 38).

Numa carta a João Gaspar Simões, datada de 11 de dezembro de 1931, Fernando Pessoa diz: «O ponto central da minha personalidade como artista é que sou um poeta dramático» (Pessoa, 1980). Fernando Pessoa

quer assim rejeitar a ideia de que é «apenas» um poeta mesmo quando escreve poesia. Em Tábua Bibliográfica, o autor afirma que a individualidade dos seus heterónimos «forma cada uma uma espécie de drama; e todas elas juntas formam outro drama» (Pessoa, 1993 [1926]), como que uma unidade dramática a que Fernando Pessoa chamou «drama em gente». Com a criação destas individualidades, não apenas literárias mas com biografia definida, várias maneiras de ser, várias estéticas, interações entre si e também com Fernando Pessoa ortónimo, o autor tinha em vista a produção de uma obra de arte total de revelação das almas.

A estreia da primeira versão cénica de $O$ Marinheiro data de 25 de setembro de 1957, pela companhia Teatro de Ensaio, na Sociedade Musical Ordem e Progresso em Lisboa. Em Portugal, a peça foi levada à cena vinte vezes entre 1960 e 2018. O Marinheiro é o texto de Fernando Pessoa mais encenado, «o que se explica não só por ser uma peça terminada, mas também por ter sido a única publicada, em 1915» (Freitas/ /Ferrari, 2017a: 25).

A par de $O$ Marinheiro, vários outros textos de Fernando Pessoa têm sido encenados. Podem agrupar-se os espetáculos, a partir da obra de Pessoa, em três categorias: encenações de textos dramáticos, encenações de textos poéticos e adaptações ou colagens de textos dramáticos e/ou poéticos. Do heterónimo Álvaro de Campos, por exemplo, foram levadas à cena, em Portugal, nove encenações de Ode Marítima entre 1986 e 2014. A par de Campos, foram encenados, em Portugal, textos de todos os heterónimos e de alguns semi-heterónimos, tornando evidente não só a urgência de ver em cena textos do autor de língua portuguesa de maior relevância do século xx, como uma intuição dos encenadores de que a poesia de Fernando Pessoa é teatralizável. A poesia pessoana tem sido constantemente editada e consequentemente encenada em Portugal e, no entanto, as obras dramáticas têm sido esquecidas; por um lado, algumas delas não foram finalizadas pelo autor ou a sua curta dimensão não permitiria a criação de um espetáculo de média duração e, por outro lado, pela parca edição e divulgação. Os catorze textos do teatro estático de Fernando Pessoa - que não constituem todos os seus textos para teatro, estando identificados mais de trinta - têm sido parcialmente publicados desde 1977, estando, desde 2017, reunidos numa edição de Filipa Freitas e Patricio Ferrari pelas Edições tinta-da-china.

Há, no entanto, outra razão para que a poesia tenha sido mais vezes levada à cena que o teatro e, mais particularmente, o teatro estático: o ritmo do texto poético permite à encenação e ao ator intercalarem 
gestos e ações; já o teatro estático «pretende revelar as almas n'aquilo que ellas conteem que não produz acção, nem se revela atravez da acção» (Pessoa, 2017a [1914-1915]: 277). No teatro estático, as falas parecem servir apenas de preparação para os grandes silêncios que traduzem o tempo do pensamento e requerem total ausência de ação. Há uma separação concreta entre corpo e alma, carne e essência, existência e consciência: a res cogitans e a res extensa traduzidas numa clara diferença entre o tempo do texto na cena e o tempo da receção do texto, da interiorização, da perfeita comunicação do texto pelo intérprete ao espetador. Fernando Pessoa pensa num teatro «higienizado» em que o silêncio e a imobilidade dos corpos são ação (por oposição à necessidade que encenador e intérpretes têm de encontrar gestos e ações que preencham o silêncio), em que a literatura e a suspensão do tempo real provocam um movimento interno que transcende o espaço teatral e traz à luz as almas: o alcance total da obra de arte. Mas Fernando Pessoa não desejava um teatro impossível, que fosse totalmente inexecutável e, portanto, a «presença do actor, da expressividade do seu corpo que segundo Pessoa, se deseja que seja como a de um "ginasta sobre a barra", sendo que a barra é o palco» (Monteiro, 2014: 18-19) é fundamental, não para a completa imobilidade do corpo, mas para que o «movimento interno que, processualmente, se traduz na amplitude que a pulsação e a respiração têm na cena» (Boléo, 2014:39) seja efetivo no constante movimento em que a memória sinestésica devolve o gesto ao corpo.

Até ao ano de 2012, a única peça de teatro de Fernando Pessoa que constituiu o texto único do espetáculo em que se inseria foi $O$ Marinheiro nas suas várias encenações. Todas as outras peças de Pessoa foram utilizadas como fragmentos dramáticos para a composição de dramaturgias que serviram os textos finais dos espetáculos que integraram. Só em 2012, a peça Inércia constituiu o texto integral de um espetáculo de curta duração com dramaturgia e encenação de Luísa Monteiro, apresentado na Sociedade Recreativa Farense - Os Artistas, no âmbito do Curtas Mostra Teatral de Peças de Curta Duração. Inércia foi depois levada à cena, em 2014, com dramaturgia e direção de atores de Ricardo Boléo.

\section{DA PALAVRA AO GESTO: A CONSTRUÇÃO DE UMA ESTÉTICA DA CENA}

Entre 2013 e 2019, dirigi quatro espetáculos a partir de peças de teatro estático de Fernando Pessoa: a mais terna ilusão (2013), dramaturgia e direção de atores de Ricardo Boléo, coprodução Teatro Turim e UmColetivo, estreou no Teatro Turim em Lisboa e foi também apresentado no Festival AMO-TEatro'14 na Camacha e no Festival Internacional de Teatro de Setúbal - XVII Festa do Teatro; Inércia (2014), dramaturgia e direção de atores de Ricardo Boléo, coprodução do Teatro Turim e UmColetivo, teve a sua antestreia no VII Festival T em Albufeira, estreou no Espaço Ribeira em Lisboa, tendo tido apresentações também no CACE Cultural do Porto, no Festival Internacional de Teatro de Setúbal - XVI Festa do Teatro e no Festival Internacional de Teatro do Alentejo 2015; A Morte do Príncipe (2016), dramaturgia e encenação de Ricardo Boléo, estreou na Sala Estúdio do Teatro da Trindade e foi apresentado no Teatro do Bolhão no Porto e no $34 .^{\circ}$ Festival de Almada; e \#Emigrantes (2019), dramaturgia e encenação de Ricardo Boléo, coprodução Em Nome do Caos e Teatro da Trindade INATEL, com estreia na Sala Estúdio do Teatro da Trindade e apresentações no Mudas.Museu de Arte Contemporânea da Madeira, no Teatro Municipal de Bragança, no Cine Teatro de Almeirim e no I Festival Iberoamericano de Teatro de Madrid.

\section{A mais terna ilusão}

A dramaturgia de a mais terna ilusão parte d'O Marinheiro de Fernando Pessoa e integra textos originais não publicados, sem título, de Cátia Terrinca e Ricardo Boléo. Partindo-se do pressuposto de que as veladoras contêm em si «dois sentimentos contraditórios: o desejo de escapar à vida em sua fortaleza, ainda que frágil, do sonho, e a angústia da sua solidão, da sua condição de exiladas, diríamos, do Tempo dos outros» (Lopes, 2004: 188. [trad. própria]) ${ }^{1}$, as três personagens foram entendidas «como uma única mulher e o texto foi adaptado a um monólogo que, na sua génese, é $O$ Marinheiro» (Boléo, 2014: 38). Optar por abdicar de uma certa coralidade que a voz coletiva das três veladoras confeririam à cena não retirou ao texto, no esboço da dramaturgia e encenação do espetáculo, a musicalidade de uma linguagem próxima da poesia. Embora se tenha individualizado uma única figura em cena, a conceção do espetáculo despersonalizava-a. Ao invés de aceder aos símbolos que Fernando Pessoa descreve na didascália inicial de $O$ Marinheiro,

No original: «deux sentiments contradictoires: le désir d'échapper à la vie dans cette forteresse, pourtant si fragile, du rêve, et l'angoisse de leur solitude, de leur situation d'exilés dirions-nous, du Temps des autres» (Lopes, 2004: 188). 


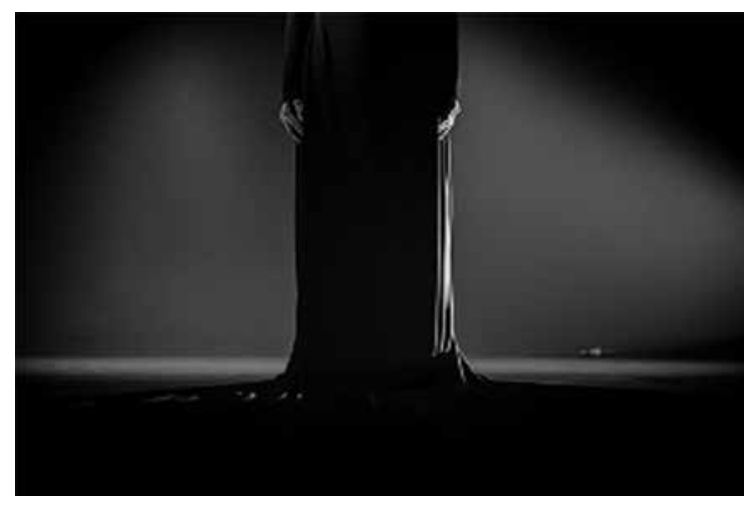

A MAIS TERNA ILUSÃO, A PARTIR DE

FERNANDO PESSOA, DIR. RICARDO BOLÉO,

TEATRO TURIM E UM COLETIVO, 2013 (CÁTIA TERRINCA), [F] ALÍPIO PADILHA

o espetador é confrontado com uma figura anónima, engrandecida por um vestido de oito metros que era, efetivamente, o único objeto de cena do espetáculo no meio de um espaço vazio. A ausência das vozes múltiplas das três veladoras foi decisiva para que o lamento singular, entre o sonho e o sono, de uma única figura em cena, em luto imóvel, se tornasse sobremaneira audível, mesmo quando sussurrava ou se dirigia a figuras ausentes, permanecendo entre o real e o irreal, incluindo os momentos de longas pausas que potenciavam situações de inércia.

A fim de demonstrar o labor dramatúrgico - que não pretendeu recodificar ou ressignificar o texto original - tome-se como exemplo as primeiras falas das veladoras de O Marinheiro (Pessoa, 2017b [1913]: 31-32):

PRIMEIRA VELADORA - Ainda não deu hora nenhuma.

SEGUNDA - Não se pode ouvir. Não ha relógio aqui perto. Dentro em pouco deve ser dia.

TERCEIRA - Não: o horizonte é negro.

PRIMEIRA - Não desejais, minha irmã, que nos entretenhamos contando o que fômos? É bello e é sempre falso...

SEGUNDA - Não, não fallemos d'isso. De resto, fômos nós alguma cousa? PRIMEIRA - Talvez. Eu não sei. Mas, ainda assim, sempre é bello falar do passado... As horas têm cahido e nós temos guardado silencio. Por mim, tenho estado a olhar para a chama d'aquella vela. Ás vezes treme, outras torna-se mais amarella, outras vezes empallidece. Eu não sei porque é que isso se dá. Mas sabemos nós, minhas irmãs, por que se dá qualquer cousa?...

(uma pausa)
A MESMA - Fallar do passado - isso deve ser bello, porque é inútil e faz tanta pena...

SEGUNDA - Fallemos, se quizerdes, de um passado que não tivéssemos tido.

TERCEIRA - Não. Talvez o tivéssemos tido...

PRIMEIRA - Não dizeis senão palavras. E tão triste fallar! É um modo tão falso de nos esquecermos!... Se passeássemos?...

TERCEIRA - Onde?

PRIMEIRA - Aqui, de um lado para o outro. Ás vezes isso vai buscar sonhos.

A peça teatral de Fernando Pessoa é reconfigurada em a mais terna ilusão ${ }^{2}$, resultando da criação «literária com a consciência de quem não pretende atualizar, mas apropriar-se da obra» (Boléo, 2014: 38), para servir a cena através do corpo e da voz de uma única intérprete:

Dentro em pouco deve ser dia. Ainda não deu hora nenhuma. O horizonte é negro. Não se pode ouvir. As horas têm caído e nós temos guardado silêncio. Mas sei eu por que se dá qualquer coisa?

(uma pausa)

Falar do passado: isso deve ser belo, porque é inútil e faz tanta pena. Falo de um passado que não tivéssemos tido. Não. Talvez o tivéssemos tido. Não são senão palavras. É tão triste falar! E se passeássemos? Aqui, de um lado para o outro. Às vezes isso vai buscar sonhos.

A estética do teatro estático, que rejeita «a estrutura tradicional dramática a partir da narrativa e valoriza o espaço, o tempo, a relatividade e a inércia» (Monteiro, 2014: 18), é o fio condutor para a encenação de a mais terna ilusão. A intérprete, com um longuíssimo figurino negro, contracenava «com o silêncio e com a luz num ambiente de mistério, em que a ocultação do gesto» (Boléo, 2014: 38) permitia que a palavra fosse ação. O estatismo, que a encenação exigiu ao corpo da atriz, tinha como objetivo que a palavra se tornasse corpórea, que o êxtase se materializasse na cena, através da possibilidade efetiva de o verbo se fazer carne. E quando o texto terminava e o silêncio definitivo se instalava, a atriz despia lentamente o figurino - como se de um casulo se tratasse $-\mathrm{e}$, nua, abandonava a cena.

2 Texto não publicado: dramaturgia de Ricardo Boléo a partir de textos de Cátia Terrinca, Fernando Pessoa e Ricardo Boléo. 


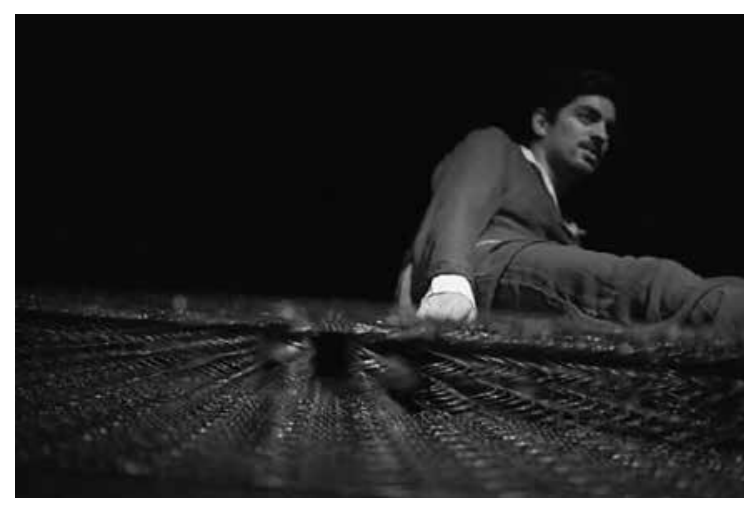

INÉRCIA, DE FERNANDO PESSOA

DIR. RICARDO BOLÉO, TEATRO TURI

E UMCOLETIVO, 2014 ( JOSÉ LEITE),

[F] ALÍPIO PADILHA

A estreia de a mais terna ilusão coincidiu com as comemorações do centenário de $O$ Marinheiro e inseriu-se num conjunto de iniciativas (teatro, música, cinema, artes plásticas e mesas-redondas) incluídas num ciclo denominado Pessoa Revisited again, que teve lugar no Teatro Turim e na Casa Fernando Pessoa em Lisboa. A abertura de Pessoa Revisited again aconteceu no dia 11 de dezembro de 2013 com a leitura pública de a mais terna ilusão pelas atrizes Cátia Terrinca, Clara Joana e Isabel Ruth.

Em 2013 escrevi Éter, com Cátia Terrinca, «no espaço contundente do ensaio, lugar absolutamente determinante da produção de identidade criativa na contemporaneidade» (Vasques, 2013: 3), sobre duas figuras que «estão num lugar metafórico que é o da espera e refletem sobre si próprias, questionando-se se deverão ou não partir» (Terrinca/Boléo, 2013a). Incluímos, no texto original, «citações explícitas da Mensagem de Fernando Pessoa, com a sua "hora" adiada» (Rosa, 2013: 35), «sendo as mesmas, estratégica e conceptualmente, empregadas a fim de enobrecer o sentido do texto» (Terrinca/Boléo, 2013b: 7). Posteriormente tivemos acesso à peça de teatro Inércia, de Fernando Pessoa - ainda inédita à época -, notando que «a convergência e a reverberação temática produzida entre ambos os textos» (Rosa, 2013:36) eram evidentes. Assim, tornou-se urgente uma montagem do texto integral de Inércia. O primeiro desafio que enfrentei, ao dirigir os atores, foi, desde logo, retomar a ideia de teatro estático enquanto estética para a cena. O texto de Pessoa funcionou como «um alicerce único que sustenta em si a possibilidade

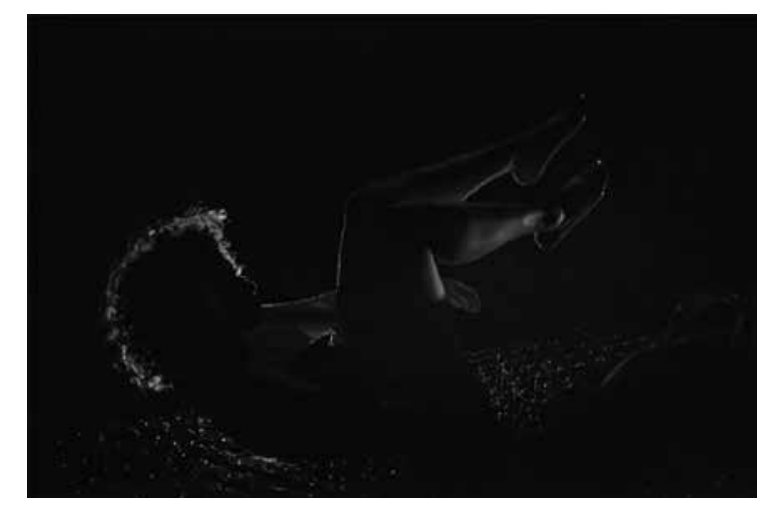

cíclica de se retomar aquilo que é dito a todo o momento» (Boléo, 2014: 39); os corpos «no espaço, destituídos de forças; possuem vontade, mas são incapazes de fazer frente à inércia» (Monteiro, 2014: 18-19). Durante grande parte do processo de ensaios, os atores foram desafiados a utilizar maquinaria, normalmente manobrada pelos performers de «estátuas vivas», para simular a levitação. Os mecanismos são de uso complexo e exigem robustez na compleição física que permita várias horas de ensaios. O uso destes aparelhos foi, no entanto, descartado, uma vez que se entendeu que uma ideia de equilíbrio dos corpos, adquirida ao longo do período de ensaios, teria uma leitura mais interessante na cenografia que, entretanto, foi adotada: um colchão descarnado onde os corpos dos atores repousavam em total inércia, utilizando o gesto como símbolo, propositalmente a rasgar o silêncio, em raros momentos do espetáculo. O facto de os atores estarem apoiados numa estrutura instável potenciava que todo o pequeno movimento dos corpos se traduzisse numa ampliação da sua plasticidade na cena. «A ironia final do dramatículo culmina, pessoanamente, no triunfo cândido da imaginação literária» (Rosa, 2014), tendo a sua tradução, no espetáculo, fabricando a ideia de Gesamtkunstwerk - «a obra de arte total» - com a execução completa de Sarabande, de Georg Friedrich Händel, permitindo que a cena transpirasse o êxtase.

\section{A Morte do Príncipe}

Na dramaturgia d'A Morte do Príncipe que deu origem ao espetáculo homónimo, utilizei a divisão de cenas que Heiner Müller estruturou para A Máquina-Hamlet, a sua leitura «furiosa» de Hamlet, de William 
Shakespeare. As partes um, dois e cinco continham excertos de $A$ Máquina-Hamlet, a parte três iniciava-se com um excerto de A Morte do Príncipe, de Fernando Pessoa, continuando com a cena I do ato III de Hamlet, de William Shakespeare, e a parte quatro era composta por Ode Triunfal, de Álvaro de Campos, intersecionada com texto de Müller.

A peça «A Morte do Príncipe foi influenciada pela obra dramática de Shakespeare» (Freitas/Ferrari, 2017a: 16), nela podemos encontrar ecos de Hamlet. A escolha da adaptação de uma cena do texto a partir das obras Hamlet e A Morte do Príncipe teve em conta, não só a possível intertextualidade entre as duas obras, como a ideia de que o Príncipe de Pessoa é, de facto, Hamlet, e as problemáticas do amor impossível e da «fronteira oscilante entre a sanidade e a loucura» (ibidem) estarem presentes em ambas as peças. O texto que se levou à cena em 2016 reescreve o erro trágico de Hamlet, «recupera, in extremis, o Príncipe moribundo do "teatro de êxtase" e do "drama extático" de Pessoa, reescreve o drama interior» (Anacleto: 2016). Realce-se que a transição textual, na dramaturgia, da passagem de A Morte do Príncipe para Hamlet tinha, no palco, um jogo mimético de troca de papéis, em que Hamlet é Ofélia e vice-versa, tornando claro o teatro dentro do teatro e «instalando, de novo e diferentemente, em cena, os fantasmas (as almas) sucessivos(as) de Hamlet» (ibidem).

Na terceira parte de A Morte do Príncipe, não houve interseção entre textos de origens diversas, mas fizeram-se algumas alterações, de modo que a linguagem ficasse mais uniforme e, portanto, verosímil. Assim, lemos em A Morte do Príncipe (Pessoa, 2017c [1914-15]: 93-94):

PRINCIPE - Sim, vou... Já tudo começa a ter outro aspecto e a fallar aos meus olhos n'uma outra voz... Parece que não sou eu que estou cansado de existir, mas as cousas que se cançam de eu as vêr... Começo a morrer nas cousas... $\mathrm{O}$ que se apaga de mim começa a apagar-se no ceu, nas arvores, no quarto, nos cortinados d'este leito... Depois, pouco a pouco, ir-se-ha apagando pelo meu corpo dentro até que fizer noite mesmo ao pé das janellas da minha alma...

$x$ - Isso é bello de mais para que possaes estar perto da morte...

PRINCIPE - É bello demais para que possa lembrar á vida... A curva dos montes, lá muito ao longe, torna-se, não mais indecisa, mas mais indecisa de outra maneira... As arvores esbatem-se em sonhos mas as folhas parecem-me extraordinariamente nitidas, evidentes de mais... A seda dos cortinados d'este leito é uma outra especie de seda... Afundo-me
A MORTE DO PRÍNCIPE, A PARTIR DE FERNANDO PESSOA, HEINER MÜLLER E DE WILLIAM SHAKESPEARE, ENC. RICARDO BOLÉO, 2016 (LÍDIA MUÑOZ), [F] TOMÁS MONTEIRO

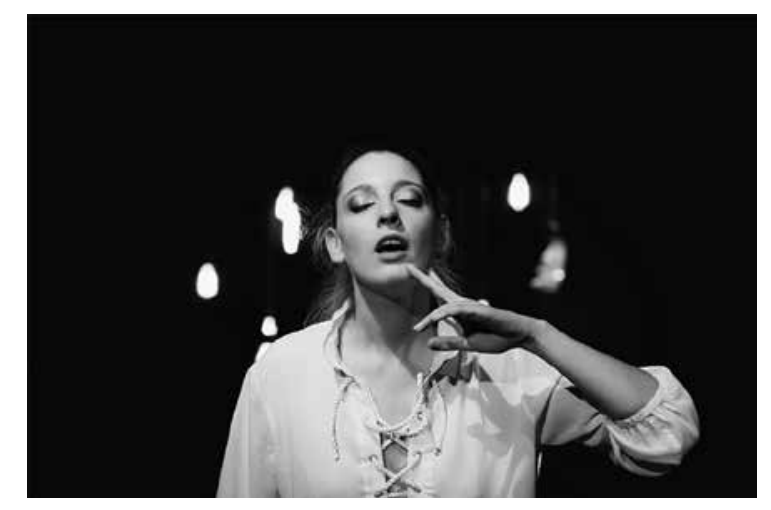

pouco a pouco... Não te entristeças... Eu era real de mais para poder reinar algum dia... O unico trono que mereço é a morte... Não dizes nada? $x$ - Senhor, não morrereis...

PRINCIPE - Sinto um ruido qualquér... Ah, como parece ser o arranjarem-me as vestes para a minha coroação no meu melhor Reyno!... Sinto tinir espadas e isso lembra-me o vêr cahir neve... Lembras-te de antigamente?... Eu era muito pequeno, e quando o silêncio da neve descia sobre a terra, iamo-nos sentar para a lareira do castello a falar nas cousas que nunca aconteceriam... Quantas princezas amei no futuro que nunca tive!... Lembras-te - não te lembras? - de como eu ficava cançado pelos combates em que nunca havia de entrar...

$x$ - Para vós, Senhor, só havia na vida amanhã...

PRINCIPE - Talvez porque o meu corpo sabia que eu teria de morrer cedo. Mas não era amanhã nunca para mim; era sempre depois de amanhã... Eu sonhava sempre com um futuro que estava sempre um pouco ao lado do futuro que eu sonhava que teria...

No texto final de A Morte do Príncipe ${ }^{3}$, além da renomeação das personagens (Principe e X passam a chamar-se Hamlet e Ofélia), são evidentes os cortes e outras pequenas alterações ao texto:

HAMLET - Sim, vou. Já tudo começa a ter outro aspeto e a falar aos meus olhos numa outra voz. Parece que não sou eu que estou cansado de existir, mas as coisas que se cansam de eu as ver. Começo a morrer nas coisas. O que se apaga de mim começa a apagar-se no céu. Depois, pouco

3 Texto não publicado: dramaturgia de Ricardo Boléo a partir de $A$ Máquina-Hamlet, de Heiner Müller, A Morte do Príncipe, de Fernando Pessoa, Hamlet, de William Shakespeare, e «Ode Triunfal», de Álvaro de Campos. 
a pouco, ir-se-á apagando pelo meu corpo dentro até se fazer noite mesmo ao pé das janelas da minha alma.

OFÉLIA - Isso é belo de mais para que possais estar perto da morte.

HAMLET - É belo demais para que possa lembrar à vida. Afundo-me pouco a pouco. Não te entristeças. Eu era real de mais para poder reinar algum dia. $O$ único trono que mereço é a morte. Não dizes nada?

OFÉLIA - Para vós, Senhor, só havia na vida amanhã.

HAMLET - Talvez porque o meu corpo sabia que eu teria que morrer cedo... Mas não era amanhã nunca para mim, era sempre depois de amanhã. Eu sonhava sempre com um futuro que estava sempre um pouco ao lado do futuro que teria.

Noutro momento do texto utilizado no espetáculo A Morte do Príncipe, intersecionam-se fragmentos de «Ode Triunfal», de Álvaro de Campos, com A Máquina-Hamlet, de Heiner Müller, tendo em vista que os versos do poema de Campos conferissem, ao monólogo dito em cena pelo Intérprete de Hamlet, um desregramento dos sentidos, uma vez que era relatado o fracasso da máquina em meio a corrupções, agressões e crises políticas na Europa. Partindo do seguinte excerto de «Ode Triunfal» (Campos, 1993 [1915]):

As dissensões domésticas, os deboches que não se suspeitam,

Os pensamentos que cada um tem a sós consigo no seu quarto

E os gestos que faz quando ninguém pode ver!

Não saber tudo isto é ignorar tudo, ó raiva,

Ó raiva que como uma febre e um cio e uma fome

Me põe a magro o rosto e me agita às vezes as mãos

Em crispações absurdas em pleno meio das turbas

Nas ruas cheias de encontrões!

Ah, e a gente ordinária e suja, que parece sempre a mesma,

Que emprega palavrões como palavras usuais,

Cujos filhos roubam às portas das mercearias

E cujas filhas aos oito anos - e eu acho isto belo e amo-o! -

Masturbam homens de aspecto decente nos vãos de escada.

A interligação dramatúrgica entre «Ode Triunfal» e algumas palavras de Müller fazia com que o monólogo, que encerrava a parte quatro do texto para a cena, se convertesse num discurso único com uma
A MORTE DO PRÍNCIPE, A PARTIR DE FERNANDO PESSOA, HEINER MÜLLER E WILLIAM SHAKESPEARE, ENC. RICARDO BOLEO, 2016 (EUNICE MUNOZZ,

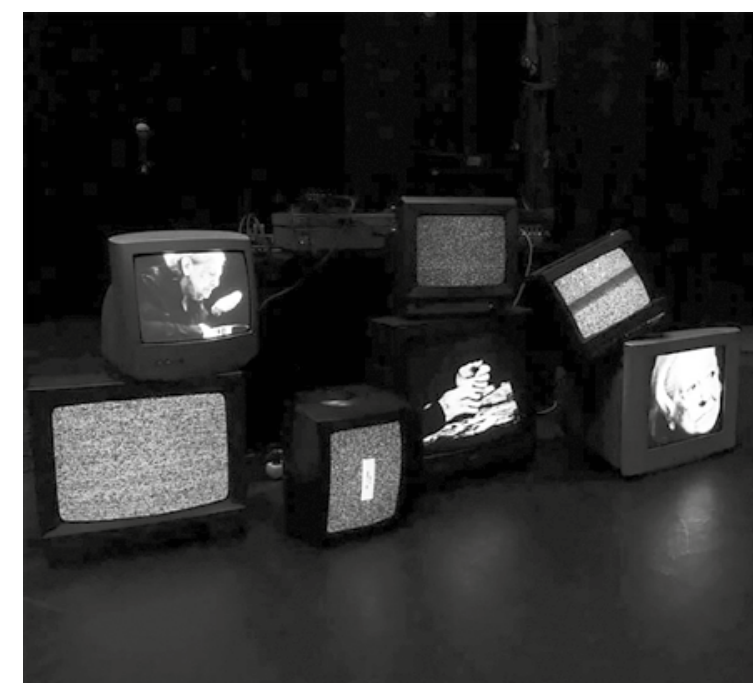

voz singular. Observe-se um exemplo das interseções que foram feitas, amiúde, no referido monólogo:

INTÉRPRETE DE HAMLET - [...] Náusea. As dissensões domésticas, os deboches que não se suspeitam, os pensamentos que cada um tem a sós consigo no seu quarto e os gestos que faz quando ninguém pode ver. Náusea. A gente ordinária e suja, que parece sempre a mesma, que emprega palavrões como palavras usuais, cujos filhos roubam às portas das mercearias e cujas filhas de oito anos - e eu acho isto belo e amo-o! - masturbam homens de aspeto decente nos vãos de escada. Como se escreve «aconchego»? [...]

Embora «Ode Triunfal» tenha momentos que suscitam a euforia na leitura, a utilização de fragmentos poéticos, em meio ao texto voraz de Müller, possibilita aos intérpretes a utilização da cadência e da respiração próprias da poesia, impondo um ritmo à cena que oscila entre o frenesi e a dilatação do tempo, conduzindo à mensura meticulosa de cada gesto. Novamente se recorreu a uma estética que invoque o teatro estático para que, nesta parte de A Morte do Príncipe - assim como ao longo de todo o espetáculo -, a palavra, os silêncios e as pausas tomassem a cena. A imobilidade, o estatismo que conduz ao êxtase, opera numa «estética da segregação corporal, ilustrada pelo movimento hidratante dos fluidos da vida e da morte, opera uma viagem obsessiva entre o dentro e o fora, o íntimo e o público» (Dionísio, 2016). Na penumbra, num 
jogo entre ficção e realidade, as figuras imóveis de Hamlet e Ofélia desapareciam, ele extenuado «torna-se um espectador da sua tragédia, incapaz de se movimentar para fora da sua esfera» (Freitas/Ferrari, 2017b: 372), impossibilitado de romper a parede imaginária entre o caos da cena e a plateia; e ela com uma máscara de oxigénio na face, como que a aspirar a réstia possível de sonho, simbolizando a esperança em meio à descrença e à destruição -, dando lugar à iluminação proveniente dos televisores que exibiam imagens da atriz Eunice Muñoz em contemplação (o seu olhar a vaguear o espaço e as suas mãos em gestos lentos) enquanto a sua voz alterada, robotizada, penetrava a cena, predominando-a, imprimindo a ideia de falência da máquina que encerrava o espetáculo.

\section{\#Emigrantes}

\#Emigrantes partia de Os Emigrantes, de Sławomir Mrożek, e integrava uma evocação ao poema Morte de Rimbaud, de Al Berto, o texto praticamente integral de $O$ s Emigrantes e uma frase de Os Estrangeiros, ambos de Fernando Pessoa. «Entrelaçando o universo dos dois poetas portugueses com o do autor polaco, diluem-se dramaturgicamente as suas vozes para que o gesto dos atores, em cena, as ecoem» (Boléo, 2019). O espetáculo era sobretudo acerca da perceção que temos de nós e dos outros, a «relação que aborda a natureza multiplicável de percepções que está em causa nos sujeitos» (Freitas/Ferrari, 2017b: 387), exponenciada por um contexto em que o migrante é estranhado por todos e ele próprio tudo estranha. Em \#Emigrantes, não era clara a origem ou o sítio onde as duas personagens estavam: a reverberação da diáspora portuguesa dialogava com as conjunturas social e política contemporâneas. $\mathrm{O}$ cenário, que tanto remetia para uma cave esquecida no subúrbio de uma grande cidade ou para o convés de um navio, punha a nu «o sentimento dilacerante de habitar um lugar estranho e inóspito» (Boléo, 2019) ou um não-lugar.

Os Emigrantes, de Fernando Pessoa, constitui toda a primeira parte de \#Emigrantes ${ }^{4}$, sendo que apenas a última fala não foi incluída. $\mathrm{Na}$ cena, os atores imóveis convocavam o espetador para o horror de uma longa noite, através de falas pontuadas com longos silêncios. $O$ primeiro gesto do espetáculo era simultâneo à primeira quebra de ritmo do

4 Texto não publicado: dramaturgia de Ricardo Boléo a partir de OS Emigrantes, de Stawomir Mrożek, Morte de Rimbaud, de Al Berto, Os Emigrantes e Os Estrangeiros, de Fernando Pessoa.
\#EMIGRANTES, A PARTIR DE AL BERTO, FERNANDO PESSOA E SLAWOMIR MROŻEK, ENC. RICARDO BOLÉO, EM NOME DO CAOS ETEATRO DA TRINDADE INATEL, 2019 (CARLOS VIEIRA), [F] TOMÁS MONTEIRO

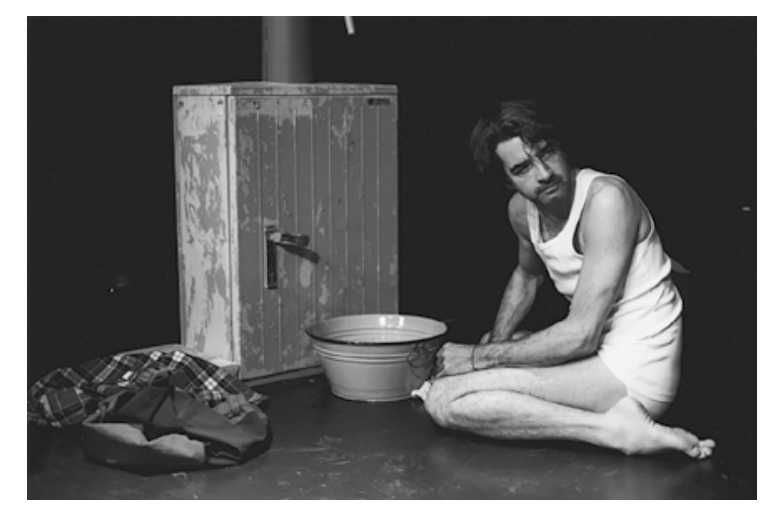

texto, imediatamente após a última (ou seja, a penúltima) fala de $O s$ Emigrantes e com o início do texto que partia da obra de Mrożek. O teatro estático de Fernando Pessoa é, posteriormente, recuperado no final de \#Emigrantes, integrando uma fala de Os Estrangeiros - «D - Tudo passa e se perde... Tudo sabe a gasto... A vida...» (Pessoa, 2017d [1916]:148) -e parte de uma fala da personagem B de Os Emigrantes - «B - Para eu te amar deveras...Posso eu amar-te deveras se não sei o que amaste? Não sei quaes fôram as paysagens do teu passado. Quem sabe se os meus gestos não tem outro rythmo que as arvores da tua terra...» (Pessoa, 2017e [1914]: 121) -, incluindo-as na fala com que a personagem V. terminava o espetáculo:

$v-[\ldots]$ A liberdade. Não é isso que queremos todos? E se todos queremos o mesmo o que é que nos impede de conseguirmos? Tudo passa e se perde. Tudo sabe a gasto. A vida... Não sei quais foram as paisagens do teu passado. Mas tu voltarás. Tu voltarás e serás livre.

Ao contrário do que aconteceu noutras experiências dramatúrgicas já relatadas, esta é a única interseção da obra de Fernando Pessoa com os textos que constituíram o ponto de partida de \#Emigrantes. Recuperar a frase de Os Emigrantes, já utilizada no início do texto, conferia uma ideia de circularidade, permitindo que o espetador tivesse a sensação de que o espetáculo poderia recomeçar no momento em que terminava, sendo que a cada recomeço seria mais caótico, doloroso e violento.

Embora se tenha utilizado muito pouco texto de Os Emigrantes e de Os Estrangeiros no monólogo final do espetáculo \#Emigrantes, a estética do teatro estático predominava em toda a última parte: os corpos dos atores regressavam à imobilidade enquanto se ouviam as suas últimas falas. 
A cena era tomada por um ambiente de mistério que permitia ver apenas dois espectros; a revelação dos segredos, a consciência de si, a perceção nítida do outro permitem a descoberta da liberdade, a revelação das almas e o êxtase.

\section{Do gesto ao silêncio: a revelação das almas}

O teatro simbolista «afrontou a estabilidade das categorias dramáticas dominantes» (Oliveira, 2003: 14) originando um teatro que seria «hostil a qualquer desdobramento cenográfico» (Roubine, 2003: 123), pelo que o texto ocupava um lugar central e o ator seria apenas veículo da palavra. «Pela primeira vez desde o classicismo, a representação se via desligada da obrigação mimética e da sujeição a um modelo inspirado no real» (Roubine, 2003: 121). A racionalização da inquietação e da abstração pela utilização da linguagem potenciam uma estética cénica que não se define pela forma literária: não se transpõe um texto para o palco ou se representa, no sentido de figurar ou expor, mas de revelar. Os textos não contêm em si a forma ou fórmula de serem interpretados, aliás «uma interpretação é tanto mais perfeita quanto mais consegue fazer esquecer o objecto interpretado na própria interpretação» (Pessoa, 1966: 179-180). Encontramos, em várias notas de Pessoa, cálculos «para a escolha das palavras exatas a fim de constituírem um determinado ritmo, passível de peso» (Monteiro, 2014: 10) e que permite uma abertura para um universo discursivo mais amplo. As palavras, no teatro estático de Fernando Pessoa, imprimem um ritmo preciso à respiração do intérprete que confere interioridade à figura em cena e dissuade a utilização de gestos pela sua inutilidade, uma vez que se tornam meramente explicativos, quase como que repetições das palavras que, por si, se bastam. «Estamos perante um teatro da inacção, cuja dinâmica se revela na tomada de consciência das personagens perante o mistério, o significado da existência, a morte» (Freitas/Ferrari, 2017b:357). O gesto, a acontecer, terá de ser tão preponderante como a palavra ou o silêncio.

O trabalho de encenação que desenvolvo é de partilha com os atores, de criação de intimidade, de ser guiado pelas suas subjetividades e integrar as suas descobertas de liberdade dentro da premissa da imobilidade dos corpos. A composição de espaço e tempo teatrais, sem recurso a dispositivos multimédia, privilegia uma cena que regressa a uma simplicidade em que o que está em evidência são «problemas fundamentais como o mistério e o desconhecido» (Freitas/Ferrari, 2017b:360). A integração do teatro estático de Fernando Pessoa na criação de texto e/ou espetáculo originais permite que uma estética cénica herdeira do teatro simbolista se materialize na cena. O público reage ao estatismo dos corpos, o ambiente que se instala é de profundo compromisso com a cena, de pacto; não há ruído na sala, o absoluto silêncio da plateia em comunhão com o espetáculo permite que o ritual que conduz ao êxtase aconteça: as palavras tomam-se de gesto e ecoam entre a eloquência dos silêncios.

\section{REFERÊNCIAS BIBLIOGRÁFICAS}

ANACLEto, Marta Teixeira (2016), Não sou Hamlet, programa do espetáculo A Morte do Príncipe.

BOLÉO, Ricardo (2019), \#Emigrantes ou não ser de um lugar no mundo, programa do espetáculo \#Emigrantes.

- (2014), «Pedra-de-Toque - A Palavra na mensura do gesto magistral», in Luísa Monteiro (ed.), Inércia, Vila Nova de Gaia, Cama de Gato, pp. 38-41.

CAmpos, Álvaro de (1993), «Ode Triunfal», in Teresa Rita Lopes (ed.), Álvaro de Campos - Livro de Versos, Lisboa, Estampa.

DiOnísio, Bruno (2016), O principe do devir, programa do espetáculo A Morte do Príncipe.

FISCHER, Claudia J., (2012), «Auto-tradução e experimentação linguística na génese d'O Marinheiro, de Fernando Pessoa», Pessoa Plural, n. ${ }^{\circ}$, junho, pp. 1-69.

FREITAS, Filipa, e FERRARI, Patricio (2017a), «Apresentação», in Filipa de Freitas e Patricio Ferrari (eds.), Teatro Estático, Lisboa, Tinta-da-china, pp. $7-26$.

- (2017b), «Posfácio», in Filipa de Freitas e Patricio Ferrari (eds.), Teatro Estático, Lisboa, Tinta-da-china, pp. 349-402 .

LOPEs, Teresa Rita (2004), Fernando Pessoa et le drame symboliste: héritage et création, Paris, Éditions de la Différence.

MONTEIRo, Luísa (2014), «O Drama enquanto extensão da Física», in Luísa Monteiro (ed.), Inércia, Vila Nova de Gaia, Cama de Gato, pp. 7-19.

OLIVEIRA, Fernando Matos (2003), Teatralidades: 12 percursos pelo território do espectáculo, Coimbra, Angelus Novus

PESSOA, Fernando (2017a), «Textos Sobre o Teatro Estático», in Filipa de Freitas / Patricio Ferrari (ed.), Teatro Estático, Lisboa, Tinta-da-china, pp. 276-279.

- (2017b), «O Marinheiro», in Filipa de Freitas e Patricio Ferrari (ed.), Teatro Estático, Lisboa, Tinta-da-china, pp. $29-47$.

- (2017c), A Morte do Príncipe, in Filipa de Freitas e Patricio Ferrari (ed.), Teatro Estático, Lisboa, Tinta-da-china, pp. 89-108.

- (2017d), Os Estrangeiros, in Filipa de Freitas e Patricio Ferrari (ed.), Teatro Estático, Lisboa, Tinta-da-china, pp. $145^{-149}$

- (2017e), Os Emigrantes, in Filipa de Freitas e Patricio Ferrari (ed.), Teatro Estático, Lisboa, Tinta-da-china, pp. 119$-122$.

- (1993), Tábua Bibliográfica, Lisboa, Contexto [ed. facsimil. 1926, revista Presença, n. ${ }^{17}$, Coimbra].

- (1980), Textos de Crítica e de Intervenção, Lisboa, Ática.

- (1966), Páginas Íntimas e de Auto-Interpretação, textos estabelecidos e prefaciados por Georg Rudolf Lind e Jacinto do Prado Coelho, Lisboa, Ática. 
ROSA, Armando Nascimento (2014), Corações literários resistem na inércia, programa do espetáculo Inércia.

- (2013), «Uma última chamada para o voo 1143», in Cátia Terrinca e Ricardo Boléo, Éter (Col. «Dramaturgos Portugueses Contemporâneos»), Amadora, Escola Superior de Teatro e Cinema, pp. 32-37.

Roubine, Jean-Jacques (2003), Introdução às grandes teorias do teatro, trad. André Telles, Rio de Janeiro, Jorge Zahar Editor.

TERRINCA, Cátia e BOLÉo, Ricardo (2013a), «Travessias em Teatro», Ensaios de Teatro, n. ${ }^{\circ}$ 2, novembro, pp. $40-41$.

- (2013b), Éter (Col. «Dramaturgos Portugueses Contemporâneos»), Amadora, Escola Superior de Teatro e Cinema.

VAsques, Eugénia (2013), «Nota de Edição», in Cátia Terrinca e Ricardo Boléo, Éter (Col. «Dramaturgos Portugueses Contemporâneos»), Amadora, Escola Superior de Teatro e Cinema, p. 3.

\section{RICARDO BOLÉO}

Mestre em Teatro pela Escola Superior de Teatro e Cinema do Instituto Politécnico de Lisboa, licenciado em Estudos Artísticos pela Faculdade de Letras da Universidade de Coimbra, frequentou as Faculdades de Comunicação, História, Letras e Teatro da Universidade Federal da Bahia no Brasil. É autor dos títulos de poesia Segredos (2007), Quem não Dormiu (2010) e memórias de sal (2013). Publicou diversos textos acerca de arte e cultura, destacando-se o artigo «Pedra-de-toque - a palavra na mensura do gesto magistral» na primeira edição de Inércia, de Fernando Pessoa (2014). Para teatro, publicou Nóbrega (2010), um volume com os textos Fuga [sem saída] e Temperantia - Estou de dieta! (2011), A Rainha de Trapos (2013) e Éter (2013). Trabalha regularmente como dramaturgista e encenador em diversos espectáculos, dos quais se destacam Temperantia - Estou de dieta! (2009), Éter (2013), a mais terna ilusão (2013), Inércia (2014), Cântico (2014), silêncio (2015), A Morte do Príncipe (2016) e \#Emigrantes (2019). 